\title{
PROPERTIES OF SOLID POLYURETHANES MADE FROM PALM OLEIN-BASED POLYOLS PREPARED WITH VARIOUS TYPES OF NUCLEOPHILES
}

\author{
TUAN NOOR MAZNEE TUAN ISMAIL ${ }^{1 *}$; NOR AZOWA IBRAHIM²; KOSHEELA DEVI POO PALAM ${ }^{1}$; \\ HOONG SENG SOI'; MOHD AZMIL MOHD NOOR ${ }^{1}$; YEONG SHOOT KIAN'; EMILIA ABD. MALEK ${ }^{2}$; \\ IBRAHIM SENDIJAREVIC ${ }^{3}$ and VAHID SENDIJAREVIC ${ }^{3}$
}

\begin{abstract}
Understanding on structure-property relationship between raw materials and resultant polyurethane (PU) products is very crucial in order to develop a product that is commercially feasible. This study is aimed to evaluate structure-property relationship of palm olein-based polyols in solid polyurethanes (SPUs). SPUs were prepared by reacting palm olein-based polyols (POoP) and 1,4-butanediol (BDO) with 4,4'-methylenebis (phenyl isocyanate) at a mole ratio of 1:1:2, respectively. Mechanical and thermal properties, phase interaction, crystallinity and solvent resistance of SPUs were evaluated. Mechanical properties and solvent resistance of SPUs were greatly influenced by hard segment concentration and crosslink density as witnessed in SPUs based on palm olein polyols made from water and methanol as nucleophiles. All SPUs are highly crystalline polymer (wide angle X-ray diffraction), thermally stable [thermogravimetric analysis (TGA)], exhibited phase-mixed morphologies between hard and soft segments [dynamic mechanical analyser $(D M A)]$ and dimensionally stable in most solvents tested. In general, SPU made from POoP H (epoxide group of epoxidised palm olein ring-opened with water) offers high hardness and SPU made from POoP EG (epoxide group of epoxidised palm olein ring-opened with 1,2-ethanediol) offers good elongation and tear strength, exhibiting the most promising and economically feasible SPUs, depending on their target applications.
\end{abstract}

Keywords: mechanical and thermal properties, palm olein-based polyols, solid polyurethanes.

Received: 20 October 2021; Accepted: 31 January 2022; Published online: 2 March 2022.

\section{INTRODUCTION}

Vegetable oils have attracted significant attentions as one of the most important platform chemicals for

\footnotetext{
Malaysian Palm Oil Board,

6 Persiaran Institusi, Bandar Baru Bangi,

43000 Kajang, Selangor, Malaysia.

2 Department of Chemistry, Faculty of Science,

Universiti Putra Malaysia,

43400 Serdang, Selangor, Malaysia.

3 Troy Polymers Inc., 900 E. Mandoline Avenue, Madison Heights, Michigan 48071, USA.

* Corresponding author e-mail: maznee@mpob.gov.my
}

chemical industry due to their availability, relatively low cost and environmental sustainability (Caillol et al., 2012; Chen et al., 2014; Lligadas et al., 2010). Vegetable oils, mainly triglycerides constituted by glycerol and three fatty acid chains, commonly contain unsaturated carbon-carbon double bonds $(-\mathrm{C}=\mathrm{C}-)$ or alkene groups that are available for further modification to form more reactive functional groups (Chen et al., 2014; Omonov et al., 2016). Many modifications of vegetable oils have been described including epoxidation, carbonation, esterification and / or transesterification, ozonolysis, etc. (Armylisas et al., 2017; Omonov et al., 2016). There are several approaches available for epoxidation of 
the alkene to obtain the epoxide, however, the most widely used method is the classical epoxidation reaction proposed by Prileschajew (Omonov et al., 2016). This reaction has two stages, whereby in the first stage, peroxy acid is generated in-situ using hydrogen peroxide and carboxylic acid, and in the second stage, the peroxy acid reacts with alkene to form epoxide. Indeed, epoxidation of vegetable oils is a matured industrial process, well controlled and less expensive (Caillol et al., 2012; Omonov et al., 2016).

The structure of vegetable oil with respect to type, composition and distribution of fatty acids in the triglycerides molecule is complex. The fatty acid profile of vegetable oil is a unique characteristic. Variability in the composition is expected even in the same type of oil, depending on the type of soil, plant and local weather conditions (Lligadas et al., 2010; Zlatanić et al., 2004). Generally, different vegetable oils have different degree of unsaturation, vegetable oils with high degree of unsaturation will have high iodine number, e.g., soybean has iodine number of 126.6; canola, 114.1; linseed, 182.0; sunflower, 133.3; corn, 125.5 (Zlatanić et al., 2004) and palm olein, $56.4 \mathrm{~g} \mathrm{I}_{2} 100 \mathrm{~g}^{-1}$ (Calliauw et al., 2007). Therefore, it is expected that polyols prepared with vegetable oils may vary in hydroxyl numbers, viscosities, hydroxyl functionalities and thermal properties, depending on the degree of unsaturation present in the oil (Lligadas et al., 2010; Zlatanić et al., 2004).

Vegetable oil-based polyols could be considered a new class of polyol in polyurethane (PU). The use of vegetable oils such as palm, soybean and canola in the development of polyols has received substantial interest due to the environmental concerns such as petrochemical-based manufacturing activities which promote air pollution, global climate change and oil spills (Lligadas et al., 2010; Petrović, 2008). PUs prepared with vegetable oil-based polyols exhibit a number of excellent properties which are attributable to hydrophobicity of vegetable oil moiety (Lligadas et al., 2010) contributed by the presence of long hydrocarbon chains in the triglycerides backbone.

Palm oil, being the most abundant vegetable oil in the world, offers a good source of raw material for preparation of vegetable oil-based polyols. In 2020, about 5.87 million hectares of oil palm was planted in Malaysia, which produced about 19.14 million tonnes of crude palm oil (Parveez et al., 2021). The development of palm oil-based polyols in Malaysia was first initiated by the Palm Oil Research Institute of Malaysia (PORIM) [now known as Malaysian Palm Oil Board (MPOB)] in early 1990s, whereby epoxidation and alcoholysis are the two main chemical reactions used to produce polyols.

Syntheses of palm olein-based polyols (POoP), in which the epoxide groups of epoxidised palm olein (EPOo) were ring-opened with water, methanol and diols (C2 to C6) were successfully carried out in the presence of borontriphluoride in diethylether catalyst (Tuan Noor Maznee et al., 2018a). It was found that the POoP had certain degree of oligomers, indicating occurrence of oligomerisation during ring-opening reaction. Epoxide group of EPOo ring-opened with water $(\mathrm{H})$, methanol $(\mathrm{M})$ and 1,2-propanediol (PG) resulted in POoP with $100 \%$ secondary hydroxyls, while, epoxide group ringopened with 1,2-ethanediol (EG), 1,3-propanediol (PDO), 1,4-butanediol (BDO), 1,5-pentanediol (PTDO) and 1,6-hexanediol (HDO) resulted in POoP with a mixture of primary $(26 \%-36 \%)$ and secondary hydroxyls $(64 \%-74 \%)$. A similar observation was also reported for polyols made from fatty acid methyl ester or winter grade biodiesel as a feedstock (Tuan Noor Maznee et al., 2018b).

Depending on their feedstock, palm oil-based polyols with variable functionalities, hydroxyl numbers and viscosities could be produced. Palm oil-based polyols have been evaluated for rigid PU foams (Tanaka et al., 2008; Tuan Noor Maznee et al., 2001). In flexible PU foam, literature reported that drop-in replacement of petrochemical-based polyol with palm oil-based polyols at certain percentage had resulted in more uniform cell size structure and improved physical properties of PU foam (Srihanum et al., 2017). Additionally, POoP and fatty acid methyl ester-based polyol (PolyFAME) could be used to make soft PU elastomers with adhesion properties (Mohd Norhisham et al., 2017).

Morphology, mechanical and thermal properties of PUs are greatly influenced by molecular weight of soft segment (SS) (Brokenbrow et al., 1971; Costa et al., 2014), chemical nature of repeating unit of SS (Drobny, 2007; Xu et al., 2015), hard segment (HS) and SS concentrations (Costa et al., 2014; Drobny, 2007) and incorporation of fillers (Cruz and Viana, 2015; Drobny, 2007). Most of the studies on the above-mentioned factors were conducted on solid polyurethanes (SPUs) because of their welldefined chemical structure (Hepburn, 1992), which effectively and in most cases, directly illustrate the structure-property relationship. SPUs are segmented linear block copolymers formed by alternating hard and soft segments. The HS is composed of urethane groups and chain extender(s), displaying strong hydrogen bonding between urethane groups, which form physical cross-linked networks, while the SS consists of a flexible polyol chain (Costa et al., 2014; Cruz and Viana, 2015).

Despite all the palm-based PU products developed so far, there is a need for a comprehensive study on properties of SPUs made from POoP in order to understand better the structure-property relationship of palm olein-based PU products. Therefore, in this study, SPUs were prepared with various types of POoP (epoxide groups were ring-opened with various types of nucleophiles), 
and their effect on the properties of SPUs were evaluated. This understanding will help to expedite the development of palm-based PU products, which have commercial viability.

\section{MATERIALS AND METHODS}

\section{Materials}

Syntheses and characterisations of palm oleinbased polyols i.e., POoP H, POoP M, POoP EG, POoP PG, POoP PDO, POoP BDO, POoP PTDO and POoP HDO have been described in details by Tuan Noor Maznee et al. (2018a). POoP H, POoP M, POoP EG, POoP PG, POoP PDO, POoP $\mathrm{BDO}, \mathrm{POoP} \mathrm{PTDO}$ and $\mathrm{POoP} \mathrm{HDO}$ were made from epoxidised palm olein whereby the epoxide groups were ring-opened with $\mathrm{H}, \mathrm{M}, \mathrm{EG}, \mathrm{PG}, \mathrm{PDO}$, BDO, PTDO and HDO, respectively. Properties of POoP are shown in Table 1. The same batches of polyols were used to make SPUs. In preparation of SPUs, 4,4'-methylenebis(phenyl isocyanate) (MDI, Mondur M from Covestro Baytown, Texas, USA) was used as an isocyanate, while BDO of $99 \%$ purity from Alfa Aesar (Ward Hill, Massachusetts, USA) was used as chain extender. For solvent resistance test of SPUs, deionised water, mineral oil (ultra grade 20, BOC Edwards Vacuum Technology, Mississauga, Canada), toluene of $99.9 \%$ purity, methyl ethyl ketone (MEK) of $99.5 \%$ purity, sodium hydroxide of $0.1 \mathrm{~N}$ (Merck, Darmstadt, Germany) and hydrochloric acid of $0.1 \mathrm{~N}$ (Fisher Chemical, Loughborough, United Kingdom) were used. All materials were used as received, unless otherwise stated.

\section{Methods}

Preparation of solid polyurethanes (SPUs). SPUs were prepared via one-shot method by reacting a mixture composed of POoP and BDO with MDI at a mole ratio of 1:1:2, respectively and an isocyanate index of 1.02. Sheet and button shaped samples of SPUs were prepared for evaluation of their mechanical properties. POoP and BDO were preheated at $80^{\circ} \mathrm{C}$ to $120^{\circ} \mathrm{C}$ prior to blending. The $\mathrm{POoP}$ and $\mathrm{BDO}$ were weighed into the speed mixer cup of $100 \mathrm{ml}$ and were mixed for $60 \mathrm{~s}$ at $2200 \mathrm{rpm}$ using a multiaxial mixer. It was subsequently placed in an air-circulating oven at $80^{\circ} \mathrm{C}$ to $120^{\circ} \mathrm{C}$ for at least 15 min. A melted MDI sample was weighed using a syringe and conditioned in an air-circulating oven at $70^{\circ} \mathrm{C}$ for at least $15 \mathrm{~min}$. All components were mixed using a multiaxial mixer at $2200 \mathrm{rpm}$ for $20 \mathrm{~s}$. At gel time, the mixture was immediately poured into an aluminium mould covered with Teflon sheets (both top and bottom). Both Teflon sheets and metal moulds were preheated at $120^{\circ} \mathrm{C}$ in an air-circulating oven. Then, it was immediately transferred into a hot press, where it was pressed for $2 \mathrm{hr}$. Finally, the prepared SPU was post-cured in an oven for $20 \mathrm{hr}$ at $100^{\circ} \mathrm{C}$. The prepared SPUs were then left for seven days at room temperature prior to testing. For designation of the SPUs, S-H, S-M, S-EG, S-PG, S-PDO, S-BDO, S-PTDO and $\mathrm{S}$-HDO were made from POoP $\mathrm{H}$, POoP M, POoP EG, POoP PG, POoP PDO, POoP BDO, POoP PTDO and $\mathrm{POoP} H D O$, respectively.

Characterisation of solid polyurethanes (SPUs). Thermal properties of SPUs were determined using differential scanning calorimetry (DSC)

\section{TABLE 1. PROPERTIES OF PALM OLEIN-BASED POLYOLS}

\begin{tabular}{|c|c|c|c|c|c|c|c|c|c|c|}
\hline \multirow[b]{2}{*}{$\begin{array}{l}\text { Sample } \\
\text { designations }\end{array}$} & \multirow[b]{2}{*}{$\begin{array}{c}\text { Carbon } \\
\text { number } \\
\text { of } \\
\text { nucleo- } \\
\text { phile }\end{array}$} & \multicolumn{8}{|c|}{ Properties } & \multirow[b]{2}{*}{$\begin{array}{c}\text { Moisture } \\
\text { content } \\
(\%)\end{array}$} \\
\hline & & $\begin{array}{c}\text { Hydroxyl } \\
\text { number } \\
(\mathrm{mg} \mathrm{KOH} \\
\left.\mathrm{g}^{-1}\right)\end{array}$ & $\begin{array}{l}\text { Primary } \\
\text { hydroxyl } \\
\text { content } \\
(\%)\end{array}$ & $\begin{array}{l}\text { Secondary } \\
\text { hydroxyl } \\
\text { content } \\
(\%)\end{array}$ & $\begin{array}{l}\text { Function- } \\
\text { ality }^{* *}\end{array}$ & $\begin{array}{c}\text { Acid } \\
\text { number } \\
\text { (mg } \\
\text { KOH } \\
\left.\mathrm{g}^{-1}\right)\end{array}$ & $\begin{array}{c}\text { Oxirane } \\
\text { oxygen } \\
\text { content } \\
(\%)\end{array}$ & $\begin{array}{c}\text { Viscosity, } \\
25^{\circ} \mathrm{C} \\
\text { (mPa.s) }\end{array}$ & $\begin{array}{c}\text { Iodine } \\
\text { number } \\
\left(\mathrm{g} \mathrm{I}_{2} 100\right. \\
\left.\mathrm{g}^{-1}\right)\end{array}$ & \\
\hline POoP H & & 158.9 & 0 & 100 & 3.50 & 2.30 & 0.03 & solid & 5.69 & 0.03 \\
\hline POoP M & $\mathrm{C} 1$ & 83.4 & 3 & 97 & 2.14 & 1.48 & 0.02 & 787 & 6.57 & 0.02 \\
\hline POoP EG & $\mathrm{C} 2$ & 110.5 & 33 & 67 & 4.74 & 1.42 & 0.03 & 5416 & 4.45 & 0.03 \\
\hline POOP PDO & C3 & 105.4 & 29 & 71 & 4.73 & 0.43 & 0.05 & 7789 & 6.55 & 0.02 \\
\hline POoP BDO & $\mathrm{C} 4$ & 121.3 & 26 & 74 & 4.38 & 0.32 & 0.02 & 4241 & 3.64 & 0.04 \\
\hline POoP PTDO & $\mathrm{C} 5$ & 118.4 & 36 & 64 & 4.54 & 0.27 & 0.04 & 4678 & 6.99 & 0.04 \\
\hline POoP HDO & C6 & 120.5 & 36 & 64 & 4.28 & 0.46 & 0.02 & 3688 & 10.63 & 0.04 \\
\hline POoP PG & $\mathrm{C} 3^{*} \mathrm{Br}$ & 119.8 & 5 & 95 & 3.96 & 1.38 & 0.02 & 3649 & 5.99 & 0.04 \\
\hline
\end{tabular}

Source: Tuan Noor Maznee et al. (2018a).

Note: ${ }^{*} \mathrm{Br}$ - branched structural diol.

${ }^{* *}$ Average functionality calculated from average equivalent weights of polyols (from measured hydroxyl numbers) and $M_{n}$ measured via GPC. 
(DSC 6000, Perkin Elmer, Massachusetts, USA), thermogravimetric analysis (TGA) (simultaneous thermal analyser, STA 6000, Perkin Elmer, Massachusetts, USA) and dynamic mechanical analyser (DMA) (Q800, TA Instruments, Delaware, USA). DSC analysis of SPU was carried out over the temperature range of -45 to $255^{\circ} \mathrm{C}$ at a heating rate of $10^{\circ} \mathrm{C} \mathrm{min} \mathrm{m}^{-1}$. In the first run, the SPU sample was heated from room temperature to $150^{\circ} \mathrm{C}$. The sample was then cooled down to $-45^{\circ} \mathrm{C}$ and it was heated again to $255^{\circ} \mathrm{C}$ (second run). Thermal property from the second run was discussed in this study. For TGA analysis, the SPU sample was heated from room temperature to $800^{\circ} \mathrm{C}$ at a heating rate of $10^{\circ} \mathrm{C} \mathrm{min}^{-1}$ under $\mathrm{N}_{2}$ gas with a flow rate of $20 \mathrm{~mL} \mathrm{~min}^{-1}$. DMA analysis of SPU (35.5 mm x $12.5 \mathrm{~mm} \times 2.5 \mathrm{~mm})$ was carried out in multi-frequency-stress mode using a single cantilever clamp at a constant frequency of $1 \mathrm{~Hz}$ and a heating rate of $3^{\circ} \mathrm{C} \mathrm{min}^{-1}$.

Hardness (Shore A and D) of samples were measured using Durometer (Westop, Nishi Tokyo Seimitsu, Japan) according to ASTM D2240-05. Resiliency of SPU was measured using a Bashore Resiliometer following ASTM D2632-79. Tensile strength and elongation at break of SPU were determined using Instron 5965 following ASTM D412-98a at room temperature. Tensile recovery was measured as a percent of sample's length recovered after 10 min of tensile testing. Tear strength (Die C) of SPU was measured following ASTM D624-00. Wide angle X-ray diffraction (WAXD) analysis of SPU was conducted using a Diffractometer, Shimadzu XRD 6000 model (Kyoto, Japan). Data were collected between $2^{\circ}$ and $50^{\circ}$ at a scanning rate of $2^{\circ} \mathrm{C} \mathrm{min}^{-1}$ with $2 \theta$ scanning, using nickel-filtered $\mathrm{Cu} \mathrm{K} \alpha$ $(\lambda=1542 \mathrm{~nm})$ at a set voltage and current of $30 \mathrm{kV}$ and $30 \mathrm{~mA}$, respectively. Degree of crystallinity of SPUs was calculated using formula as reported by Shetranjiwalla et al. (2017):

$$
\text { Degree of crystallinity }=\frac{\mathrm{Ac}}{\mathrm{Ac}+\mathrm{Aa}} \times 100
$$

where Ac is the area under the crystal diffraction peaks and Aa is the area under the amorphous halo.

Solvent resistance of SPU was carried out on the specimen with a dimension of $10 \times 40 \times 2 \mathrm{~mm}$, which was immersed in deionised water, mineral oil, toluene, MEK, hydrochloric acid $(0.1 \mathrm{~N})$ and sodium hydroxide $(0.1 \mathrm{~N})$ at room temperature $\left(28^{\circ} \mathrm{C}\right)$. The weight change of the specimen was recorded after day 1 and day 7 .

\section{RESULTS AND DISCUSSION}

SPUs were produced via reaction of POoP with $\mathrm{MDI}$ in the presence of BDO chain extender through a one-shot method. Schematic reaction between POoP using POoP EG as representation, BDO and MDI to form SPU. The POoP used in this study have been previously prepared through epoxidation and alcoholysis reactions (Tuan Noor Maznee et al., 2018a), whereby the properties of the POoP are shown in Table 1. All SPUs had HS concentrations of $31 \%$ to $46 \%$ (Table 2), depending on the hydroxyl number of the POoP (Table 1).

TABLE 2. PROPERTIES OF SPUs

\begin{tabular}{|c|c|c|c|c|c|c|c|c|}
\hline Composition & S-H & S-M & S-EG & S-PDO & S-BDO & S-PTDO & S-HDO & S-PG \\
\hline Polyol & POoP H & POoP M & POoP EG & POoP PDO & POoP BDO & POoP PTDO & POoP HDO & POoP PG \\
\hline \# of $\mathrm{C}$ atoms in nucleophile & & $\mathrm{C} 1$ & $\mathrm{C} 2$ & $\mathrm{C} 3$ & $\mathrm{C} 4$ & $\mathrm{C} 5$ & C6 & $\mathrm{C} 3{ }^{*} \mathrm{Br}$ \\
\hline $\begin{array}{l}\text { Hard segment } \\
\text { concentration (\%) }\end{array}$ & 46 & 31 & 39 & 36 & 39 & 39 & 40 & 40 \\
\hline \multicolumn{9}{|l|}{ Properties } \\
\hline Hardness (Shore A) & $89 \pm 2$ & $69 \pm 2$ & $86 \pm 2$ & $89 \pm 2$ & $88 \pm 2$ & $89 \pm 2$ & $92 \pm 2$ & $89 \pm 2$ \\
\hline Hardness (Shore D) & $29 \pm 1$ & $17 \pm 1$ & $25 \pm 1$ & $29 \pm 2$ & $28 \pm 1$ & $31 \pm 1$ & $34 \pm 1$ & $30 \pm 1$ \\
\hline Resilience $(\%)$ & $9.2 \pm 0.1$ & $14.6 \pm 0.2$ & $11.4 \pm 0.2$ & $11.2 \pm 0.4$ & $11.6 \pm 0.3$ & $10.9 \pm 0.2$ & $11.8 \pm 0.4$ & $12.1 \pm 0.6$ \\
\hline $\begin{array}{l}\text { Tensile strength at break } \\
\text { (MPa) }\end{array}$ & $22.4 \pm 0.8$ & $\mathrm{n} / \mathrm{a}$ & $15.3 \pm 0.7$ & $11.5 \pm 0.3$ & $16.9 \pm 0.6$ & $15 \pm 0.3$ & $17.0 \pm 0.7$ & $17.1 \pm 1.0$ \\
\hline $\begin{array}{l}\text { Tensile set (recovery of } \\
\text { length after } 10 \mathrm{~min})(\%)\end{array}$ & $8.0 \pm 3.7$ & $\mathrm{n} / \mathrm{a}$ & $5.8 \pm 0.6$ & $3.3 \pm 0.2$ & $4.7 \pm 0.6$ & $4.1 \pm 1.2$ & $5.0 \pm 0.6$ & $4.9 \pm 0.6$ \\
\hline Elongation at break (\%) & $20.5 \pm 8.4$ & $\mathrm{n} / \mathrm{a}$ & $26.0 \pm 4.1$ & $28.6 \pm 2.0$ & $26.2 \pm 3.7$ & $28.3 \pm 2.1$ & $33.3 \pm 2.9$ & $29.6 \pm 4.5$ \\
\hline Tear strength $\left(\mathrm{N} \mathrm{cm}^{-1}\right)$ & $1906 \pm 50$ & $191 \pm 3$ & $1017 \pm 68$ & $640 \pm 38$ & $1006 \pm 31$ & $852 \pm 104$ & $986 \pm 105$ & $966 \pm 30$ \\
\hline $\begin{array}{l}\text { Melt transition temperature } \\
\left({ }^{\circ} \mathrm{C}\right)\end{array}$ & 11 & 7 & $\begin{array}{l}\text { no melting } \\
\text { peak }\end{array}$ & $\begin{array}{l}\text { no melting } \\
\text { peak }\end{array}$ & $\begin{array}{l}\text { no melting } \\
\text { peak }\end{array}$ & $\begin{array}{l}\text { no melting } \\
\text { peak }\end{array}$ & $\begin{array}{l}\text { no melting } \\
\text { peak }\end{array}$ & $\begin{array}{l}\text { no melting } \\
\text { peak }\end{array}$ \\
\hline Enthalpy of fusion $\left(\mathrm{Jg}^{-1}\right)$ & 3.14 & 7.28 & $\mathrm{n} / \mathrm{a}$ & $\mathrm{n} / \mathrm{a}$ & $\mathrm{n} / \mathrm{a}$ & $\mathrm{n} / \mathrm{a}$ & $\mathrm{n} / \mathrm{a}$ & $\mathrm{n} / \mathrm{a}$ \\
\hline
\end{tabular}

Note: $\mathrm{n} / \mathrm{a}$ - not available (SPU sample was soft); ${ }^{*} \mathrm{Br}$ - branched structural diol; \pm - standard deviation. 


\section{Mechanical Properties of SPUs}

Mechanical properties of SPUs were measured in terms of hardness, resilience, elongation at break, tensile and tear strengths. Generally, hardness of SPUs increased with increasing diol chain length (from C2 to C6). The hardness was highest in SPU made from POoP HDO of C6 diol (Table 2). In the case of $\mathrm{S}-\mathrm{H}$, high hardness observed was due to the relatively higher HS concentration in this SPU $(46 \%)$ as a result of higher hydroxyl number (Table 1). Higher tensile and tear strengths and lower resilience and elongation at break in $\mathrm{S}-\mathrm{H}$ were also observed due to the higher concentration of HS. Conversely, the SPU labelled as S-M, which was made from POoP M, with the lowest hydroxyl number and functionality, had exhibited the lowest hardness and tear strength, as expected, due to the lower cross-link density as indicated by lowest functionality of this polyol (Table 1) and lowest HS concentration (Table 2). The tensile strength and elongation at break of S-M could not be measured because the SPU was too soft (the sample failed at the grip point of the clamp). No significant effect between structure of diol [linear (PDO) vs. branched diol (PG)] was observed on the hardness, resilience and elongation at break of SPU. In general, there was no significant difference in the mechanical properties among SPUs made from POoPs, which were prepared with diols of different chain length. This might be due to the chemical structure of triglycerides, that is relatively larger than the chemical structure of diols used in this study, which minimise the influence of the diol's structure on the properties of SPUs.

\section{Thermal Behaviour and Dynamic Properties of SPUs}

Thermal behaviour of SPUs was analysed using DSC, TGA and DMA. Melt transitions measured by DSC were observed in S-H and S-M, which were made from POoP $\mathrm{H}$ and $\mathrm{POoP} \mathrm{M}$, respectively. The melt transitions of S-H and S-M were observed at $11^{\circ} \mathrm{C}$ and $7{ }^{\circ} \mathrm{C}$, with the enthalpy of fusion of 3.14 and $7.28 \mathrm{~J} \mathrm{~g}^{-1}$, respectively. There was no thermal transition observed in SPUs made from other POoP, in which the epoxide groups were ring-opened with diols (Figure 1). This would suggest that the polyol SS had mixed sufficiently with the HS, which completely distrupted the crystallinity of the polyol segment. Similar observations were reported by Caillol et al. (2012) and Del Rio et al. (2010).

Thermal decomposition temperature $\left(T_{d}\right)$ (onset) of SPUs was measured using TGA. The thermal decomposition of SPUs started at about $259^{\circ} \mathrm{C}$ to $304^{\circ} \mathrm{C}$ (Table 3, Figure 2) depending on the types of nucleophiles used during epoxide ring-opening reaction of the $\mathrm{POoP}$, initiated by the decomposition of urethane groups at around $290^{\circ} \mathrm{C}$ (Datta and Kasprzyk, 2018) and $238^{\circ} \mathrm{C}-286^{\circ} \mathrm{C}$ (Tuan Noor Maznee et al., 2019). $T_{d}$ of SS is initiated by a random scission of the ester linkage at around $370^{\circ} \mathrm{C}$ (Datta and Kasprzyk, 2018) and $360^{\circ} \mathrm{C}$ to $386^{\circ} \mathrm{C}$ (Tuan Noor Maznee et al., 2019). In this study, $T_{d}$ of SS was observed around $350^{\circ} \mathrm{C}$ to $427^{\circ} \mathrm{C}$ due to a random scission of both ester and ether linkages as the POoP structurally have both ester and ether linkages (Tuan Noor Maznee et al., 2018a). It was observed that SPUs made from POoP, prepared with epoxide groups ring-opened with diols, had higher $T_{d}$ than epoxide groups ring-opened with $\mathrm{H}$ and $\mathrm{M}$ (Table 3).

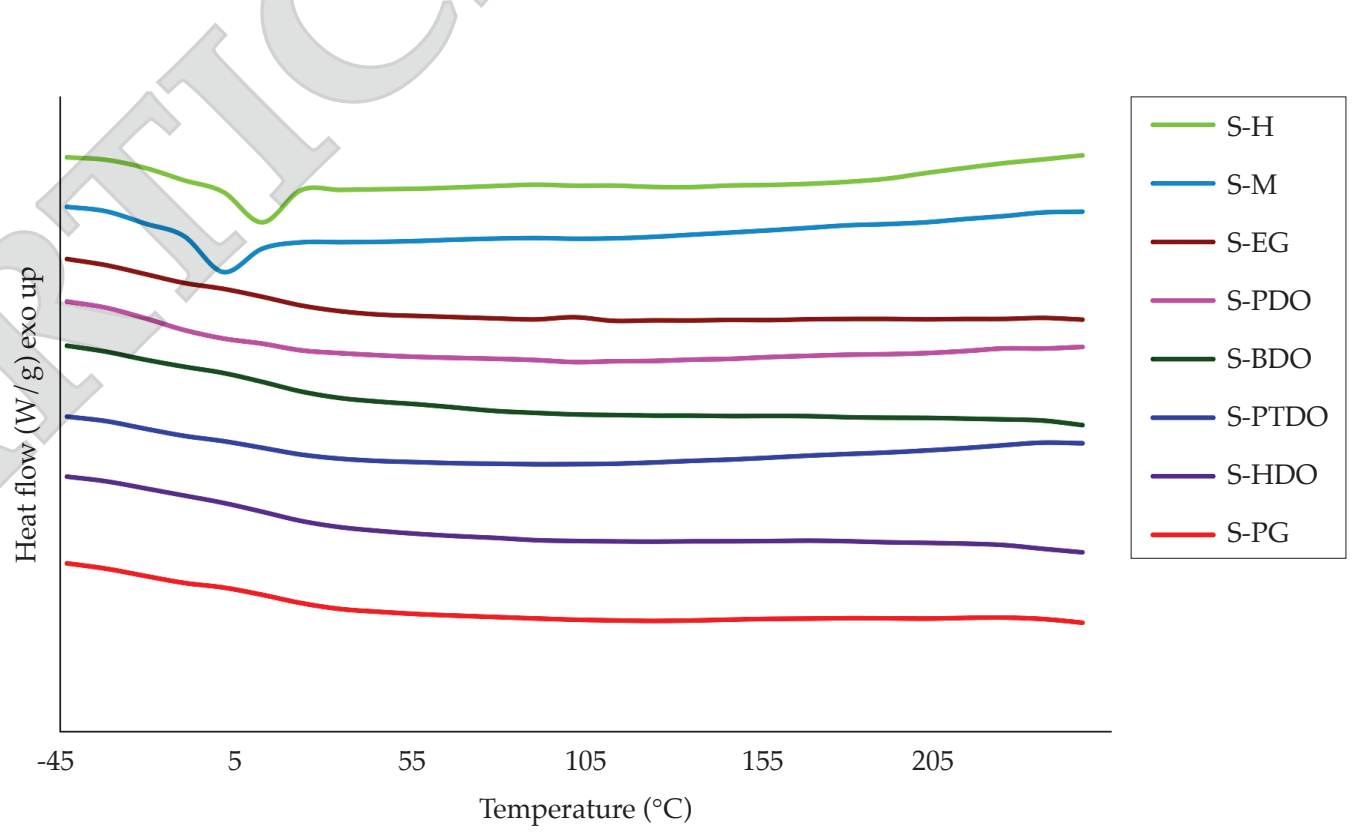

Figure 1. DSC thermograms of SPUs made from palm olein-based polyols. 


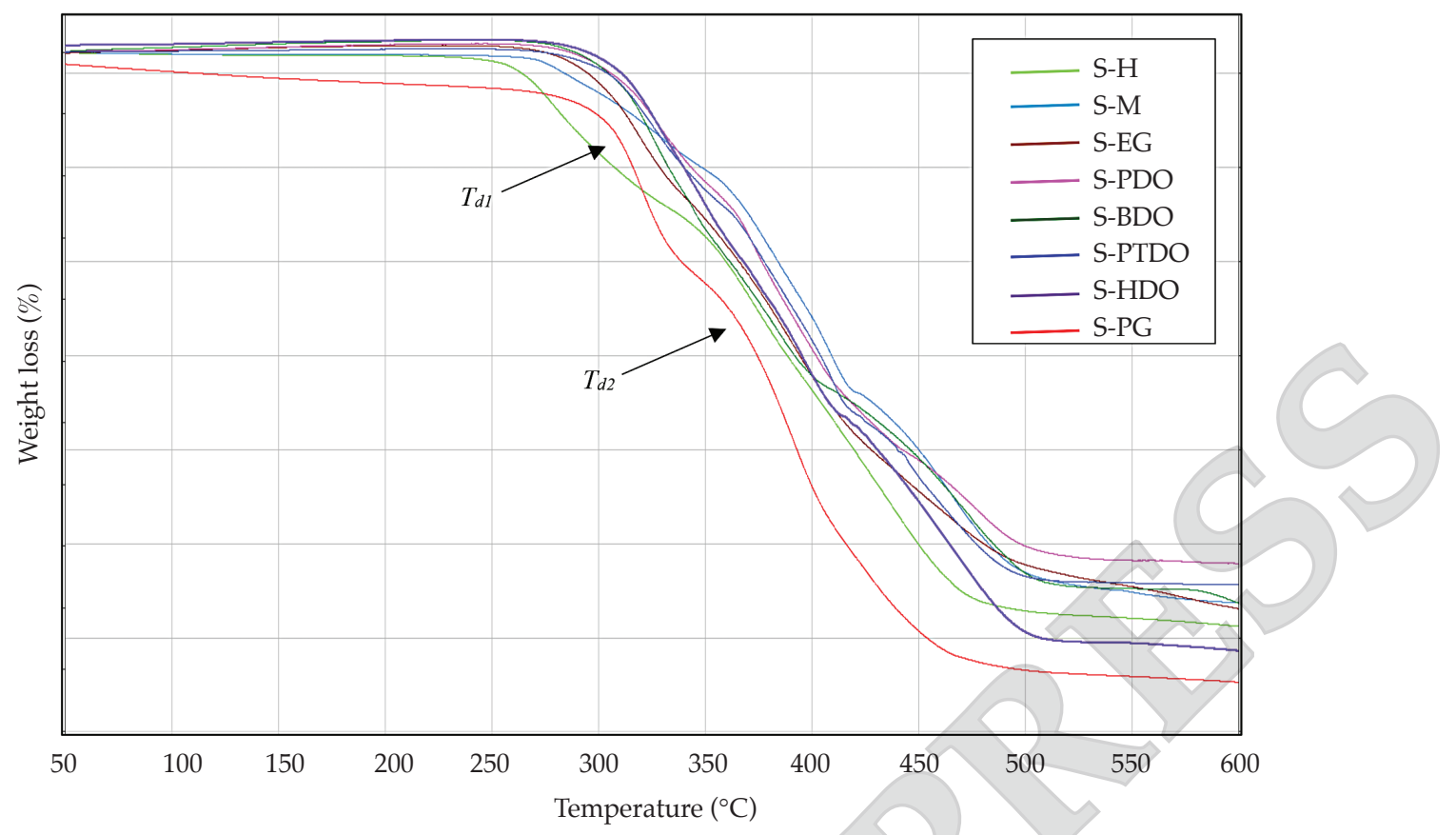

Figure 2. TGA thermograms of SPUs made from palm olein-based polyols.

TABLE 3. THERMAL DECOMPOSITION OF SPUS MADE FROM PALM OLEIN-BASED POLYOLS

\begin{tabular}{lcc}
\hline SPU & $\begin{array}{c}\text { Thermal } \\
\text { decomposition, } \boldsymbol{T}_{\boldsymbol{d} \mathbf{}^{\prime}}{ }^{\circ} \mathrm{C}\end{array}$ & $\begin{array}{c}\text { Thermal } \\
\text { decomposition, } \boldsymbol{T}_{\boldsymbol{d} \mathbf{2}^{\prime}}{ }^{\circ} \mathbf{C}\end{array}$ \\
\hline S-H & 259 & 351 \\
S-M & 271 & 364 \\
S-EG & 292 & 367 \\
S-PDO & 300 & 363 \\
S-BDO & 300 & 377 \\
S-PTDO & 298 & 366 \\
S-HDO & 304 & 427 \\
S-PG & 300 & 368 \\
\hline
\end{tabular}

Thermodynamic properties of the SPUs determined using DMA are as shown in Figures 3 and 4 . A gradual decrease in storage modulus of the SPUs was observed as the temperature was increased from $-100^{\circ} \mathrm{C}$ to $100^{\circ} \mathrm{C}$ (Figure 3). At low temperature region $\left(-100^{\circ} \mathrm{C}\right.$ to $\left.0^{\circ} \mathrm{C}\right)$, all SPUs displayed the same storage modulus, except S-M, which was made from POoP with almost $100 \%$ secondary hydroxyl groups which had the lowest hydroxyl number and functionality (Table 1). This indicates that the S-M had lower degree of crosslinking in comparison to other SPUs. At higher temperature region $\left(0^{\circ} \mathrm{C}\right.$ to $\left.100^{\circ} \mathrm{C}\right)$, S-M exhibited the largest reduction in storage modulus due to the low degree of crosslinking, while S-H exhibited the least reduction, which could be due to the high HS concentration of this SPU, i.e., 46\% (Table 2).
Other SPUs exhibited insignificant difference in storage modulus, indicating that different chain length of diols (C2 to C6) used in ring-opening reaction of epoxide groups to form POoP did not affect the storage moduli of the prepared SPUs. Broad tan $\delta$ peaks of SPUs were observed (Figure 4), which could be attributed to the presence of amorphous and crystalline domains. It was observed that the $\tan \delta$ peak shifted to a higher temperature region in SPUs made from POoP, in which the epoxide groups were ring-opened with water and diols. The overall height of the $\tan \delta$ peak decreased due to the increased presence of the crystalline domains that impacted the dynamic properties of the SPUs. The $\tan \delta$ peak could also be ascribed to phase interaction, whereby a narrow $\tan \delta$ peak indicates phase separation between the HS and SS, while a broad $\tan \delta$ peak suggests phase mixing morphology (Hojabri et al., 2010; Sonnenschein et al., 2010; Xie et al., 2009). In this study, all SPUs exhibited phase-mixed morphologies.

\section{Diffraction Pattern and Crystallinity of SPUs}

Diffraction pattern and crystallinity of SPUs were further evaluated using WAXD analysis at $25^{\circ} \mathrm{C}$. Overall, the WAXD patterns of all SPUs showed that all the prepared samples were of highly crystalline polymers (Figure 5). There were also two main crystalline peaks observed at $2 \theta$ in the range of $13^{\circ}$ and $16^{\circ}$ with $d$-spacing in between $6.35 \AA$ to $6.39 \AA$ and $5.30 \AA$ to $5.32 \AA$, respectively. 
In terms of relative intensity of the diffraction peak at $2 \theta=13^{\circ}$, it had decreased with the increasing carbon chain length of the diol which was used to prepare $\mathrm{POoP}$, from $\mathrm{C} 1$ (methanol in S-M) to C6 (1,6-HDO in S-HDO). Overall, with different types of nucleophiles used during ring-opening reaction of epoxide groups to make POoPs, the SPUs obtained did not exhibit significant difference in the $d$-spacing, crystallite size and degree of crystallinity of the SPU samples (Table 4).

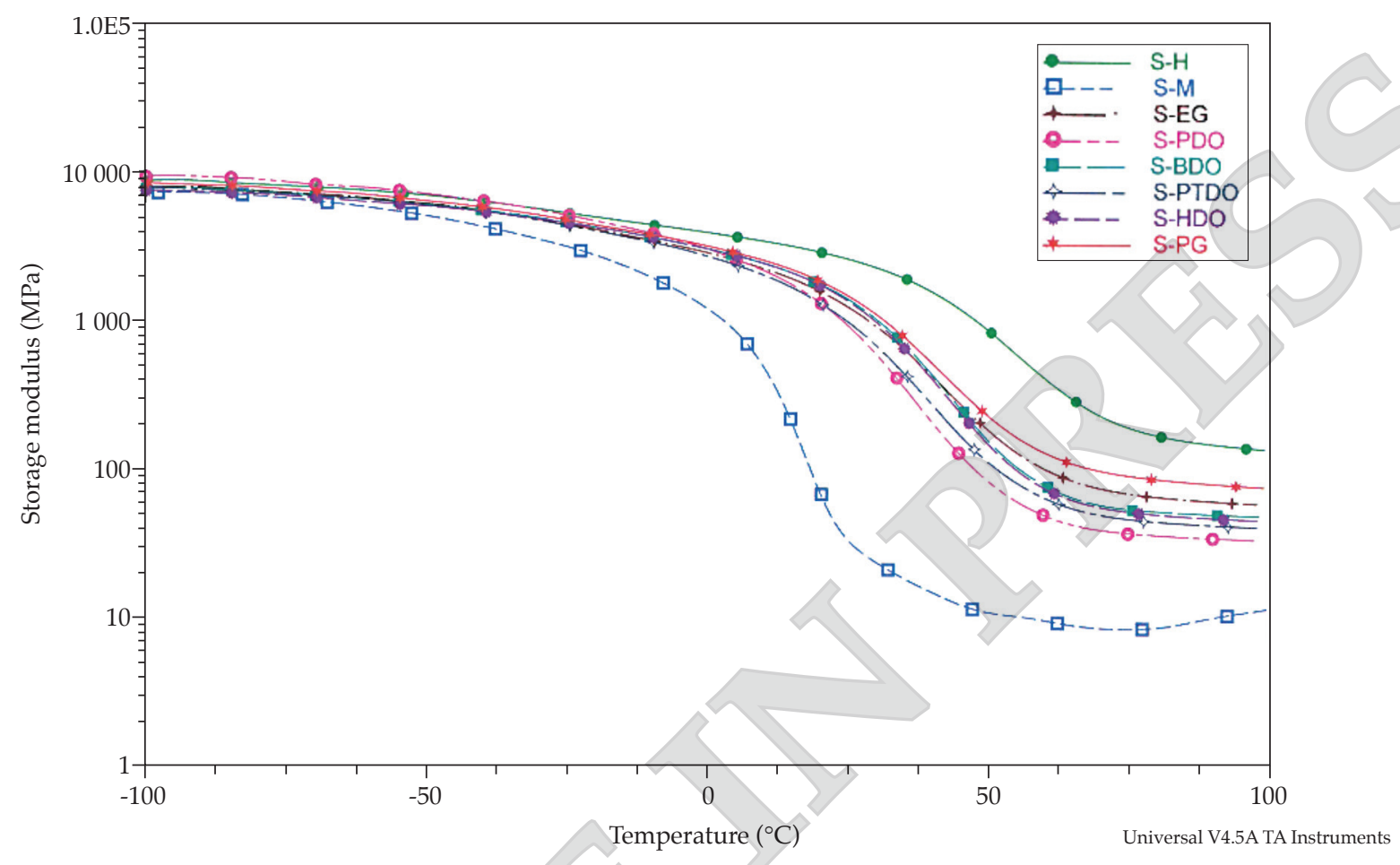

Figure 3. Temperature dependence of storage modulus for SPU made from palm olein-based polyols.

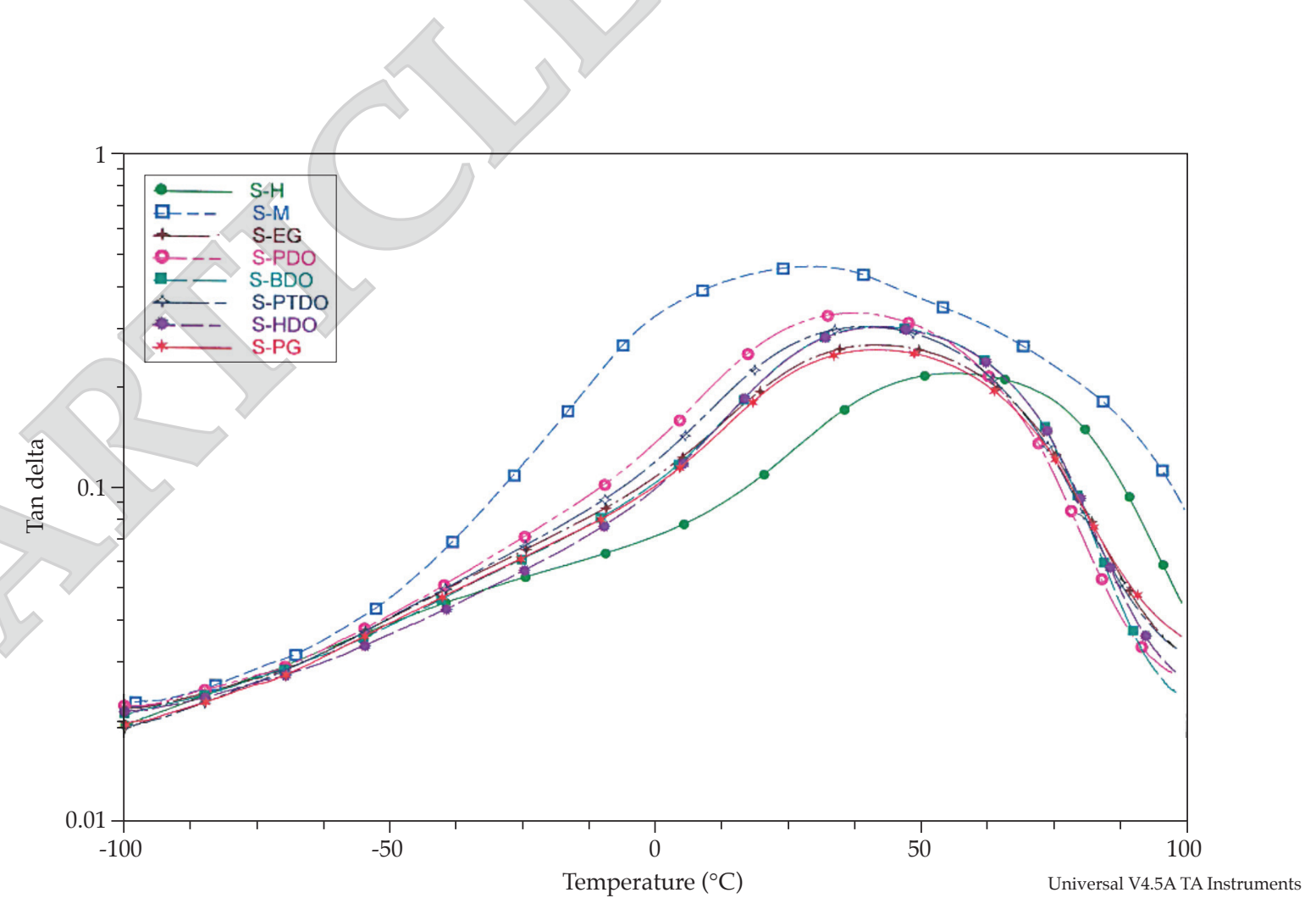

Figure 4. Temperature dependence of tan $\delta$ for SPU made from palm olein-based polyols. 


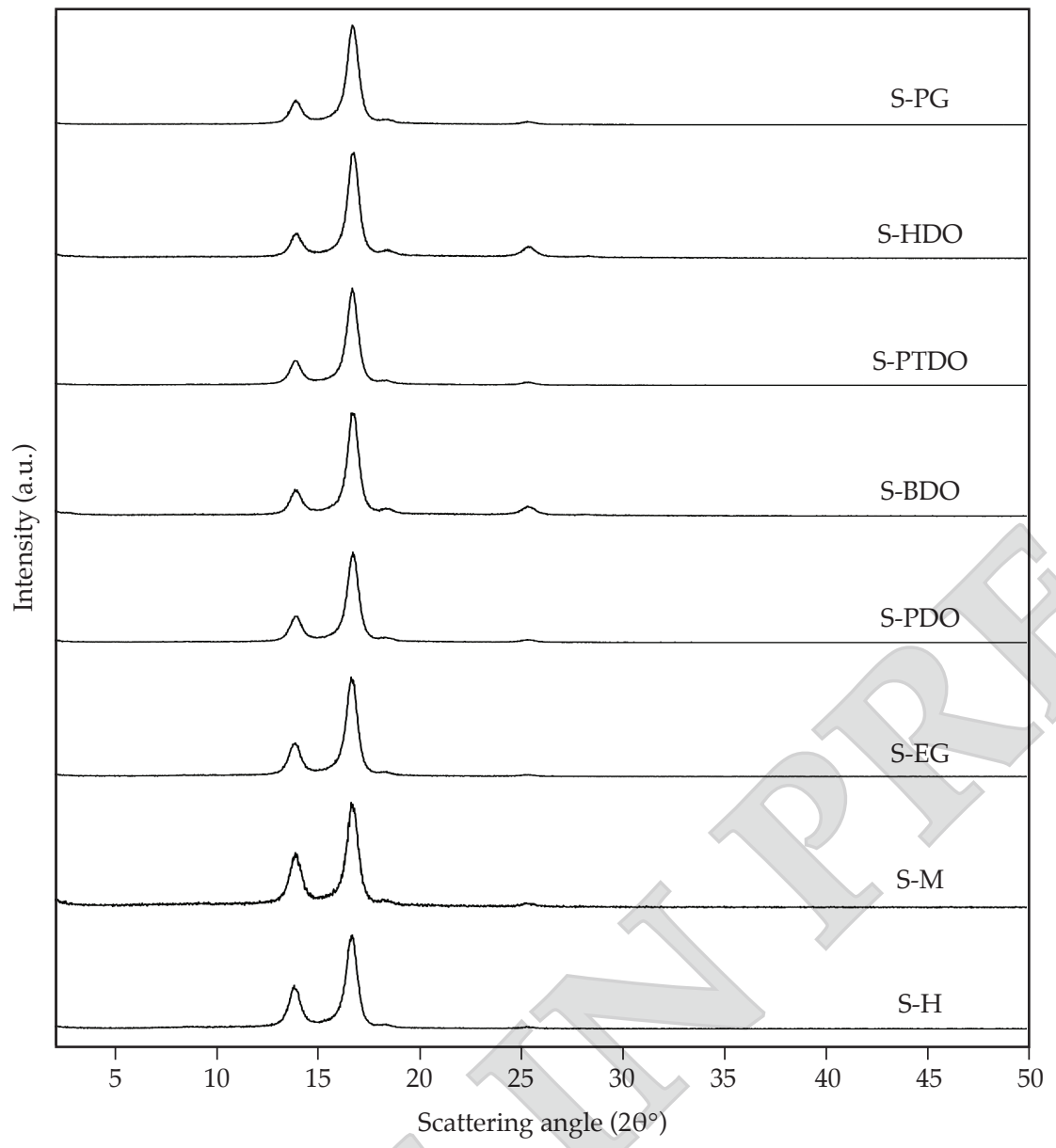

Figure 5. Wide angle X-ray diffraction (WAXD) diffractograms of SPU made from palm olein-based polyols, measured at $25^{\circ} \mathrm{C}$.

TABLE 4. SCATTERING ANGLE, $d$-SPACING, RELATIVE INTENSITY, FWHM, CRYSTALLITE SIZE AND CRYSTALLINITY OF SPU MADE FROM PALM OLEIN-BASED POLYOLS (two main peaks)

\begin{tabular}{|c|c|c|c|c|c|c|c|c|c|}
\hline \multicolumn{2}{|c|}{ Designation } & S-H & S-M & & S-PDO & \multirow{2}{*}{$\frac{\text { S-BDO }}{13.91}$} & \multirow{2}{*}{$\frac{\text { S-PTDO }}{13.89}$} & \multirow{2}{*}{$\frac{\text { S-HDO }}{13.92}$} & \multirow{2}{*}{$\begin{array}{r}\text { S-PG } \\
13.91\end{array}$} \\
\hline Peak 1 & Scattering angle, $2 \theta\left(^{\circ}\right)$ & 1201 & 13.89 & 13.85 & 13.90 & & & & \\
\hline & $d$-spacing $(\AA)$ & 6.39 & 6.37 & 6.39 & 6.36 & 6.36 & 6.37 & 6.35 & 6.36 \\
\hline & Relative intensity & 43 & 48 & 32 & 28 & 23 & 25 & 21 & 23 \\
\hline & FWHM, $2 \theta\left(^{\circ}\right)$ & 0.6889 & 0.7189 & 0.7071 & 0.6975 & 0.7004 & 0.6778 & 0.6941 & 0.7046 \\
\hline & Crystallite size (nm) & 12.14 & 11.63 & 11.83 & 11.99 & 11.94 & 12.34 & 12.05 & 11.87 \\
\hline \multirow[t]{5}{*}{ Peak 2} & Scattering angle, $2 \theta\left(^{\circ}\right)$ & 16.63 & 16.68 & 16.64 & 16.70 & 16.71 & 16.67 & 16.72 & 16.69 \\
\hline & $d$-spacing $(\AA)$ & 5.32 & 5.31 & 5.32 & 5.30 & 5.30 & 5.31 & 5.30 & 5.31 \\
\hline & Relative intensity (\%) & 100 & 100 & 100 & 100 & 100 & 100 & 100 & 100 \\
\hline & FWHM, $2 \theta\left(^{\circ}\right)$ & 0.6716 & 0.6828 & 0.6682 & 0.6743 & 0.6610 & 0.6623 & 0.6630 & 0.6889 \\
\hline & Crystallite size (nm) & 12.49 & 12.29 & 12.55 & 12.44 & 12.69 & 12.67 & 12.65 & 12.18 \\
\hline \multicolumn{2}{|c|}{ Degree of crystallinity (\%) } & 92 & 90 & 93 & 95 & 94 & 95 & 95 & 94 \\
\hline
\end{tabular}

Note: FWHM - full width at half maximum.

\section{Solvent Resistance of SPUs}

The resistance of SPUs towards solvents was evaluated in water, $0.1 \mathrm{~N}$ hydrochloric acid $(\mathrm{HCl})$, $0.1 \mathrm{~N}$ sodium hydroxide $(\mathrm{NaOH})$, toluene, mineral oil and MEK. Percentages of weight changes of SPUs after day 1 and day 7 were recorded. In general, all SPUs samples had good resistance toward water, acid $(0.1 \mathrm{~N} \mathrm{HCl})$, base $(0.1 \mathrm{~N} \mathrm{NaOH})$ and mineral oil, indicated by the low percentages of weight changes 
$(0.04 \%$ to $0.69 \%)$, except S-H and S-M, which had slightly higher percentage of weight changes in mineral oil, between $1.18 \%$ and $8.07 \%$ (Table 5). All the SPUs samples were swollen in toluene and MEK, indicated by the higher percentages of weight changes $(41.88 \%$ to $101.17 \%$ in toluene and $33.89 \%$ to $92.65 \%$ in MEK), which showed that all the SPUs were less resistant to non-polar organic solvents. In both toluene and MEK, the S-M exhibited the highest weight change due to the lower degree of crosslinking or hydrogen bonding presence in this SPU (Ionescu, 2005). This observation correlated well with POoP M structure, in which the polyol had the lowest hydroxyl number and functionality with almost 100\% secondary hydroxyl and one methoxy group hanging in the triglyceride molecule (Tuan Noor Maznee et al., 2018a).

In the case of $\mathrm{S}-\mathrm{H}$, even though it also has $100 \%$ secondary hydroxyl, the SPU displayed relatively low weight change in both toluene and MEK. This might be due to higher degree of crosslinking present in the S-H, contributed by high hydroxyl number and functionality of POoP H (Tuan Noor Maznee et al., 2018a), which help in increasing the crosslinking density of SPU (Ionescu, 2005).

\section{CONCLUSION}

POoPs have been used to prepare SPUs by reacting the polyols with MDI and chain extended with BDO. The prepared SPUs were evaluated in terms of mechanical, dynamic and morphological properties, thermal behaviour and solvent resistance. HS concentration and crosslink density seems to greatly influence the mechanical properties of the SPUs as witnessed in S-H and S-M. HS concentration is dependent on the hydroxyl number of polyol, in which polyol with higher hydroxyl number will generate higher concentration of HS and physical crosslinking. All SPUs exhibited phase-mixed morphologies between the HS and SS as indicated by DMA analysis. All SPUs were of highly crystalline polymer as shown by WAXD analysis. The solvent resistant test indicated that SPUs made from POoPs were dimensionally stable in most solvents tested except in toluene and MEK. Overall, properties of SPUs were not significantly affected by number of carbon atoms in nucleophiles used to make POoPs, however, they were significantly affected by HS concentration and crosslink density of SPU. Therefore, from commercial point of view, SPUs made from POoP $\mathrm{H}$ (water as the nucleophile) and POoP EG (1,2-ethanediol as the nucleophile) could serve as the most economical POoPs to be produced whereby SPU that requires high hardness could be produced using POoP $\mathrm{H}$ and SPU which requires high elongation and tear strength could be produced using POoP EG.

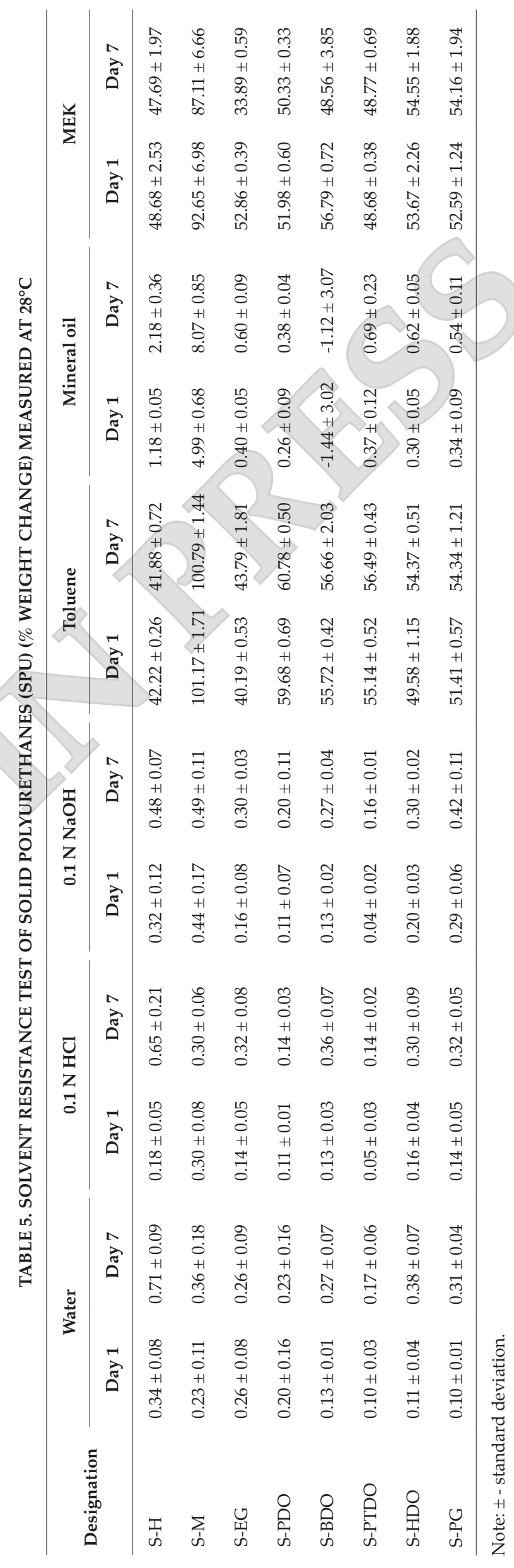




\section{ACKNOWLEDGEMENT}

The authors would like to thank the DirectorGeneral of MPOB for permission to publish this article. The authors would also like to acknowledge Norhidayah Ahmad Yusoff, Muhammad Ihsan Ismail, Mohamed Ahir Musa, Asura Abd Rahman, Mohd Taib Samsudin and Ahmad Syafiq Ahmad Hazmi of the Advanced Oleochemical Technology Division, MPOB for their technical assistance.

\section{REFERENCES}

Armylisas, A H N; Siti Hazirah, M F; Yeong, S K and Hazimah, A H (2017). Modification of olefinic double bonds of unsaturated fatty acids and other vegetable oil derivatives via epoxidation: A review. Grasas y Aceites, 68: e174.

Brokenbrow, B E; Sims, D and Wright, J (1971). Relationships between polyurethane elastomer structure and ageing properties Part 2: Effect of backbone polyol. Technical Report No. 53, Ministry of Defence, Explosives Research and Development Establishment, 1971. http://www.dtic.mil/dtic/ tr/fulltext/u2/745982.pdf, accessed on 20 February 2017.

Caillol, S; Desroches, M; Boutevin, G; Loubat, C; Auvergne, R and Boutevin, B (2012). Synthesis of new polyester polyols from epoxidised vegetable oils and biobased acids. Eur. J. Lipid Sci. Technol., 114: 1447-1459.

Calliauw, G; Gibon, V; De Greyt, W; Plees, L; Foubert, I and Dewettinck (2007), Phase composition during palm olein fractionation and its effect on soft PMF and superolein quality. J. Amer. Oil Chem. Soc., 84: 885-891.

Chen, R; Zhang, C and Kessler, M R (2014). Polyols and polyurethanes prepared from epoxidised soybean oil ring-opened by polyhydroxy fatty acids with varying $\mathrm{OH}$ numbers. J. Appl. Polym. Sci., 132: 41213.

Costa, V; Nohales, A; Felix, P; Guillem, C; Gutiérrez, D and Gómez, C M (2014). Structureproperty relationships of polycarbonate diol-based polyurethanes as a function of soft segment content and molar mass. J. Appl. Polym. Sci., 132: 41704.

Cruz, S M and Viana, J C (2015). Structure-property relationships in thermoplastic polyurethane elastomer nanocomposites: Interactions between polymer phases and nanofillers. Macromol. Mater. Eng., 300: 1153-1162.
Datta, J and Kasprzyk, P (2018). Thermoplastic polyurethanes derived from petrochemical or renewable resources: A comprehensive review. Polym. Eng. Sci., 58: E14-E35.

Del Rio, E M; Lligadas, G; Ronda, J C; Galià, M and Cádiz, V (2010). Bio-based polyurethanes from polyether polyols obtained by ionic-coordinative polymerisation of epoxidised methyl oleate. J. Polym. Sci. A Polym. Chem., 48: 5009-5017.

Drobny, J G (2007). Handbook of Thermoplastic Elastomers. First edition. William Andrew Inc, New York. 215 pp.

Hepburn, C (1992). Trends in polyurethane elastomer technology. Iranian J. Polym. Sci. Technol., 1(2): 84-110.

Hojabri, L; Kong, X and Narine, S S (2010). Functional thermoplastics from linear diols and diisocyanates produced entirely from renewable lipid sources. Biomacromolecules, 11: 911-918.

Ionescu, M (2005). Chemistry and Technology of Polyols for Polyurethanes. Rapra Technology Limited, Shawbury, Shropshire, United Kingdom. p. 32-41.

Lligadas, G; Ronda, J C; Galià, M and Cadiz, V (2010). Plant oils as platform chemicals for polyurethane synthesis: Current state-of-the-art. Biomacromolecules, 11: 2825-2835.

Mohd Norhisham, S; Sendijarevic, I; Tuan Noor Maznee, T I; Nurul 'Ain, H; Kosheela Devi, P P; Srihanum, A; Norhayati, M N; Yeong, S K; Hazimah, A H; Schiffman, C M; Sendijarevic, A and Sendijarevic, V (2017). Soft polyurethane elastomers with adhesion properties based on palm olein and palm oil fatty acid methyl ester polyols. Int. J. Adhes. Adhes., 73: 38-44.

Omonov, T S; Kharraz, E and Curtis, J M (2016). The epoxidation of canola oil and its derivatives. RSC Adv., 6: 92874-92886.

Parveez, G K A; Azmil Haizam, A T; Shamala, S; Loh, S K; Meilina, O-A; Kosheela Devi, P P; Kamalrudin, M S; Sheilyza, M I and Zainab, I (2021). Oil palm economic performance in Malaysia and R\&D progress in 2020. J. Oil Palm Res., 33(2): 181-214.

Petrović, Z S (2008). Polyurethanes from vegetable oils. Polym. Rev., 48(1): 109-155.

Shetranjiwalla, S; Li, S; Bouzidi, L and Narine, S $S$ (2017). Impact of polymerisation protocol on 
structure-property relationships of entirely lipidderived poly(ester urethane)s. J. Renew. Mater., 5(5): 333-344.

Sonnenschein, M F; Guillaudeu, S J; Landes, B $\mathrm{G}$ and Wendt, B (2010). Comparison of adipate and succinate polyesters in thermoplastic polyurethanes. Polymer, 51: 3685-3692.

Srihanum, A; Sendijarevic, I; Tuan Noor Maznee, T I; Nurul 'Ain, H; Kosheela Devi, P P; Mohd Norhisham, S; Yeong, S K; Zainab, I; Campara, I; Schiffman, C M; Pietrzyk, K and Sendijarevic, V (2017). Impact of the hard-segment concentration on highly resilient polyurethane foams based on palm olein polyol. J. Appl. Polym. Sci., 134(45): 45440 .

Tanaka, R; Hirose, S and Hatakeyama, H (2008). Preparation and characterisation of polyurethane foams using a palm oil-based polyol. Bioresour. Technol., 99: 3810-3816.

Tuan Noor Maznee, T I; Ibrahim, N A; Sendijarevic, V; Sendijarevic, I; Schiffman, C M; Hoong, S S; Mohd Noor, M A; Kosheela Devi, P P; Yeong, S K; Zainab, I; Emilia, A M; Norhazlin, Z and Sendijarevic, A (2019). Thermal and mechanical properties of thermoplastic urethanes made from crystalline and amorphous azelate polyols. J. Appl. Polym. Sci., 136: 47890 .

Tuan Noor Maznee, T I; Ibrahim, N A; Mohd Noor, M A; Hoong, S S; Kosheela Devi, P P; Yeong, S K;
Zainab, I; Schiffman, C M; Sendijarevic, I; Emilia, A M; Norhazlin, Z and Sendijarevic, V (2018a). Oligomeric composition of palm olein-based polyols: The effect of nucleophiles. Eur. J. Lipid Sci. Technol., 120(4): 1700354.

Tuan Noor Maznee, T I; Ibrahim, N A; Mohd Noor, M A; Hoong, S S; Kosheela Devi, P P; Yeong, S K; Zainab, I; Schiffman, C M; Sendijarevic, I; Emilia, A M; Norhazlin, Z and Sendijarevic, V (2018b). Oligomeric composition of polyols from fatty acid methyl ester: The effect of ring-opening reactants of epoxide groups. J. Amer. Oil Chem. Soc., 95(4): 509-523.

Tuan Noor Maznee, T I; Norin, Z K S; Ooi, T L; Salmiah, A and Gan, L H (2001). Effect of additives on palm-based polyurethane foams. J. Oil Palm Res., 13: 7-15.

Xie, R; Bhattacharjee, D and Argyropoulos, J (2009). Polyurethane elastomers based on 1,3 and 1,4-bis(isocyanatomethyl)cyclohexane. J. Appl. Polym. Sci., 113: 839-848.

Xu, W; Zhou, L; Sun, W; Zhang, J and Tu, W (2015). Effect of difunctional acids on the physicochemical, thermal and mechanical properties of polyester polyol-based polyurethane coatings. J. Appl. Polym. Sci., 132: 41246.

Zlatanić, A; Lava, C; Zhang, W and Petrović, Z S (2004). Effect of structure on properties of polyols and polyurethanes based on different vegetable oils. J. Polym. Sci. B Polym. Phys., 42: 809-819. 